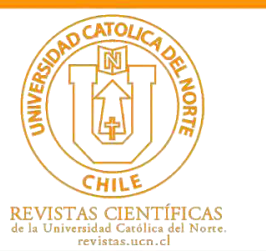

\title{
Redefined Zagreb indices of Rhombic, triangular, Hourglass and Jagged-rectangle benzenoid systems
}

\author{
Mohanad A. Mohammed ${ }^{1}$ (1) orcid.org/0000-0002-7507-1212 \\ Raad S. Haoer ${ }^{2}$ \\ Ashaq $\mathrm{Ali}^{3}$ \\ Maqbool Ahmad ${ }^{4}$ \\ Mohammad Reza Farahani ${ }^{5}$ (i) orcid.org/0000-0003-2185-5967

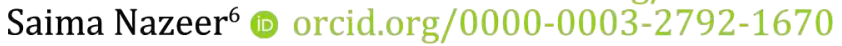

Open Educational College, Dept. of Mathematics, Al Qadisiya Centre, Ministry of Education, Amarah, Iraq. 1】mohanadalim@gmail.com; 2 raadsehen@gmail.com

The University of Lahore, Dept. of Mathematics and Statistics, Lahore, Pakistan

3曰arhamusman2001@gmail.com; 4凶maqboolchaudhri@gmail.com

Iran University of Science and Technology, Dept. of Applied Mathematics, Tehran, Iran.

5@mrfarahani88@gmail.com

Lahore College for Woman University, Dept. of Mathematics, Lahore, Pakistan.

6酒 saimanazeer123@yahoo.com

Received: February 2020 | Accepted: May 2020

\begin{abstract}
:
In the fields of mathematical chemistry and chemical graph theory, a topological index generally called a connectivity index is a kind of a molecular descriptor that is calculated in perspective of the molecular graph of a chemical compound. Topological indices are numerical parameters of a graph which depict its topology and are graph invariant up to graph isomorphism. Topological indices are used for example in the progression of quantitative structure-activity relationships (QSARs) in which the common activity or distinctive properties of atoms are connected with their molecular structure. There are in excess of 140 topological indices but none of them totally describe the molecular compound completely so there is dependably a space to characterize and register new topological indices. Benzenoid Systems are utilized basically as an intermediate to make different synthetic compounds. In this report we aim to compute redefined Zagreb indices for Zigzag, Rhombic, triangular, Hourglass and Jagged-rectangle Benzenoid systems.
\end{abstract}

Keywords:Topological index; Zagreb index; Benzenoid system..

MSC (2020): 05C10, 05C12, 05C15, 05C22, 05C31.

\section{Cite this article as (IEEE citation style):}

M. A. Mohammed, R. S. Haoer, A. Ali, M. Ahmad, M. R. Farahani, and S. Nazeer, "Redefined Zagreb indices of Rhombic, triangular, Hourglass and Jagged-rectangle benzenoid systems", Proyecciones (Antofagasta, On line), vol. 39, no. 4, pp. 851-867, Aug. 2020, doi: 10.22199/issn.0717-6279-2020-04-0053.

Article copyright: (C) 2020 Mohanad A. Mohammed, Raad S. Haoer, Ashaq Ali, Maqbool Ahmad, Mohammad Reza Farahani, and Saima Nazeer. This is an open access article distributed under the terms of the Creative Commons License, which permits unrestricted use and distribution provided the original author and source are credited. 


\section{Introduction}

Benzenoid hydrocarbons assume a fundamental job in our environment, and in the food and chemical ventures. Benzenoid molecular graph are systems with erased hydrogens. It is a connected geometric figure acquired by organizing congruent regular hexagons in a plane, so two hexagons are either disjointed or have a common edge. This considers separates the plane along with one infinite (external) region and various finite (internal) regions. Every interior regions must be regular hexagons. Benzenoid systems are of significant significance in chemistry since they are the natural graph representation of benzenoid system. A vertex of a hexagonal system has a place with, at most, three hexagons. A vertex shared by three hexagons is called an internal vertex [2]. In this paper we study redefined Zagreb indices for three Benzenoid systems, namely Zigzag, Rhombic, triangular, Hourglass and Jagged-rectangle benzenoid systems.

Chemical reaction network theory manages an endeavor to model the behavior of real world chemical systems. From the earliest starting point of its establishment, it is hot cake for look into network; particularly because of its significance in two imperative branch i.e. theoretical chemistry and biochemistry. It has additionally a critical place in pure mathematics especially because of its mathematical structures.

Cheminformatics is an up and coming and dynamic area that arrangements with the connections of quantities structure activity (QSAR) and structure property (QSPR) and furthermore predicts the biochemical activities and properties of benzenoid systems see [4]. In these examinations, for the forecast of bioactivity of the molecular compound, some physciochemical properties and topological indices are utilized see [3,20].

Mathematical chemistry is the branch of chemistry which examines the chemical structures with the guide of mathematical tools. Molecular graph is a simple graph in chemical graph theory. This graph comprises of atoms and chemical bonds and they are spoken to by vertices and edges respectively. For the connection of vertex set $\mathrm{V}(\mathrm{G})$ and edge set $\mathrm{E}(\mathrm{G})$ of a graph, there must be a presence of connecting between any pair of vertices in $\mathrm{G}$. The distance between two vertices $\mathrm{u}$ and $\mathrm{v}$ is denoted as $\mathrm{d}(\mathrm{u}, \mathrm{v})$ and it is the shortest length among $\mathrm{u}$ and $\mathrm{v}$ in graph $\mathrm{G}$. The degree of vertex is the number of vertices of $\mathrm{G}$, adjacent to given vertex $\mathrm{v}$ and will be denoted by $\mathrm{d}(\mathrm{v})$.

Numerous mathematical polynomials have productive activities in mathematical chemistry, for example, Hosoya Polynomial figures some critical 
distance based topological indices. Degree based topological indices are determining by M-polynomial which is presented in 2015. This polynomial has been on the fundamental zones of enthusiasm for computational aspects of substances. Numerous topological indices can be calculated by utilizing M-polynomial see $[11,15,16,17]$. The topological index of a compound can be utilized to evaluate the molecular structure and it branches design from numerous points of view. To be basic, the topological index can be viewed as a capacity that appoint each molecular structure to real number see $[19,21]$. Boiling point, heat of evaporation, heat of formation, chromatographic retention times, surface tension, vapor pressure and so forth can be anticipated by utilizing topological indices. First and second Zagreb indices are degree based graph invariants have been considers broadly since the 1970's. In 1998, Bollobas and Erdos presents general Randić index, which is generalization of Randić index and has been examined broadly by both mathematician and chemists. Another variation of Randić index is the harmonic index and it is helpful for calculating formation of alkanes $[7,14]$.

In 1972, the first and second Zagreb indices, $\mathrm{M}_{1}$ and $\mathrm{M}_{2}$ were found to occur inside certain approximate expressions for the total $\pi$-electron energy [13]. In 1975, these graph invariants were proposed to be measures of branching of the carbon-atom skeleton [12]. The name "Zagreb index" (or, all the more decisively, "Zagreb aggregate index") is by all accounts originally utilized in the review article [5]. The Zagreb indices are defined as:

$$
M_{1}(G)=\sum_{u v \in E(G)}\left(d_{u}+d_{v}\right)
$$

and

$$
M_{2}(G)=\sum_{u v \in E(G)}\left(d_{u} \times d_{v}\right) .
$$

Ranjini et al. [18] redefines the Zagreb index, ie, the redefined first, second and third Zagreb indices of graph $G$. These indicators appear as

$$
\begin{gathered}
\operatorname{ReZG}(G)=\sum_{u v \in E\left(P D_{1}\right)} \frac{d_{u}+d_{v}}{d_{u} \cdot d_{v}} \\
\operatorname{ReZG}_{2}(G)=\sum_{u v \in E\left(P D_{1}\right)} \frac{d_{u} \cdot d_{v}}{d_{u}+d_{v}} \\
\operatorname{ReZG}_{3}(G)=\sum_{u v \in E\left(P D_{1}\right)}\left(d_{u} \cdot d_{v}\right)\left(d_{u}+d_{v}\right) .
\end{gathered}
$$


In this report we study redefined Zagreb indices of Rhombic, triangular, Hourglass and Jagged-rectangle benzenoid systems.

\section{Computational Results}

In this section, we give our computational results.

\subsection{Triangular Benzenoid system}

In terms of chemical graph theory and mathematical chemistry, we associate a graph with the molecular structure where vertices correspond to atoms and edges to bonds. Triangular Benzenoid system denoted by $T_{p}$ is shown in figure 1. It can be observed by counting method that $\left|V\left(T_{p}\right)\right|=p^{2}+$ $4 p+1$, and $\left|E\left(T_{p}\right)\right|=\frac{3}{2} p(p+3)$. In the following theorem we compute redefined Zagreb indices for Triangular Benzenoid system.

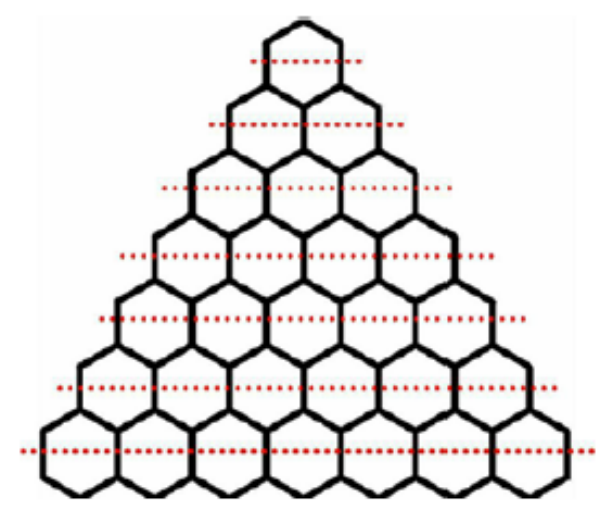

Figure 2.1: Triangular Benzenoid [2]

Theorem 2.1. LetT $T_{p}$ e a Triangular benzenoid system where $p$ shows the number of hexagons in the base graph and total no of hexagons in $T_{p}$ is $\frac{1}{2} p(p+1)$. Then 
1. $\operatorname{Re} Z G_{1}\left(T_{p}\right)=p^{2}+4 p+1$.

2. $\operatorname{Re} Z G_{2}\left(T_{p}\right)=\frac{9}{4} p^{2}+\frac{99}{20} p-\frac{6}{5}$.

3. $\operatorname{Re} Z G_{3}\left(T_{p}\right)=81 \mathrm{p}^{2}+99 p-84$.

Proof. Let $T_{p}$ be a Triangular benzenoid system. Then the edge partition of $T_{p}$ based on the degree of end vertices is given in Table 2.1.

Table 2.1: Edge Partition of Triangular benzenoid system

\begin{tabular}{|c|c|}
\hline$\left(d_{u}, d_{v}\right)$ & No of edges \\
\hline$(2,2)$ & 6 \\
\hline$(2,3)$ & $6(p-1)$ \\
\hline$(3,3)$ & $\frac{3}{2} p(p-1)$ \\
\hline
\end{tabular}

Now

1. $\operatorname{Re} Z G_{1}\left(T_{p}\right)=\sum_{u v \in E\left(T_{p}\right)} \frac{d_{u}+d_{v}}{d_{u} \cdot d_{v}}$

$$
\begin{aligned}
& =\sum_{u v \in E_{\{2,2\}}\left(T_{p}\right)}^{\frac{2+2}{2 \cdot 2}}+\sum_{u v \in E_{\{2,3\}}\left(T_{p}\right)} \frac{2+3}{2 \cdot 3}+\sum_{u v \in E_{\{3,3\}}\left(T_{p}\right)} \frac{3+3}{3 \cdot 3} \\
& =\left|E_{\{2,2\}}\left(T_{p}\right)\right| \frac{4}{4}+\left|E_{\{2,3\}}\left(T_{p}\right)\right| \frac{5}{6}+\frac{6}{9}\left|E_{\{3,3\}}\left(T_{p}\right)\right| \\
& =p^{2}+4 p+1 .
\end{aligned}
$$

2. $\operatorname{Re} Z G_{2}\left(T_{p}\right)=\sum_{u v \in E\left(T_{p}\right)} \frac{d_{u} \cdot d_{v}}{d_{u}+d_{v}}$

$$
\begin{aligned}
& =\sum_{u v \in E_{\{2,2\}}\left(T_{p}\right)} \frac{2 \cdot 2}{2+2}+\sum_{u v \in E_{\{2,3\}}\left(T_{p}\right)} \frac{2 \cdot 3}{2+3}+\sum_{u v \in E_{\{3,3\}}\left(T_{p}\right)} \frac{3 \cdot 3}{3+3} \\
& =\left|E_{\{2,2\}}\left(T_{p}\right)\right| \frac{4}{4}+\left|E_{\{2,3\}}\left(T_{p}\right)\right| \frac{6}{5}+\frac{9}{6}\left|E_{\{3,3\}}\left(T_{p}\right)\right| \\
& =\frac{9}{4} p^{2}+\frac{99}{20} p-\frac{6}{5} .
\end{aligned}
$$

3. $\operatorname{Re} Z G_{3}\left(T_{p}\right)=\sum_{u v \in E\left(T_{p}\right)}\left(d_{u} \cdot d_{v}\right)\left(d_{u}+d_{v}\right)$

$$
\begin{aligned}
& =\sum_{u v \in E_{\{2,2\}}\left(T_{p}\right)}(2 \cdot 2)(2+2)+\sum_{u v \in E_{\{2,3\}}\left(T_{p}\right)}(2 \cdot 3)(2+3) \\
& +\sum_{u v \in E_{\{3,3\}}\left(T_{p}\right)}(3 \cdot 3)(3+3) \\
& =16\left|E_{\{2,2\}}\left(T_{p}\right)\right|+30\left|E_{\{2,3\}}\left(T_{p}\right)\right|+54\left|E_{\{3,3\}}\left(T_{p}\right)\right| \\
& =81 \mathrm{p}^{2}+99 p-84 .
\end{aligned}
$$




\subsection{Zigzag Benzenoid System}

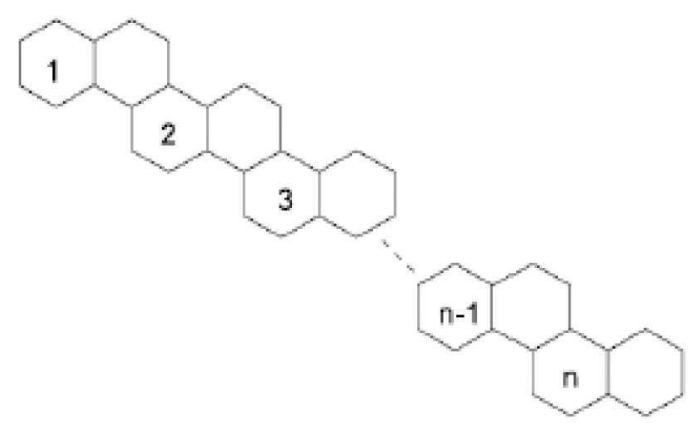

Figure 2.2: Graph of zigzag benzenoid system $Z_{p}$, [2]

Zigzag benzenoid system is denoted by $Z_{p}$, where $\mathrm{n}$ is the number of rows in graph of $Z_{p}$ and each row consists of two hexagons as shown in Figure 2. Zigzag benzenoid system has the following three partitions given in Table 2.2 .

Table 2.2: Edge Partition of Zigzag benzenoid system

\begin{tabular}{|l|c|}
\hline$\left(d_{u}, d_{v}\right)$ & No of edges \\
\hline$(2,2)$ & $2 p+4$ \\
\hline$(2,3)$ & $4 p$ \\
\hline$(3,3)$ & $4 p-3$ \\
\hline
\end{tabular}

Theorem 2.2. Consider a Zigzag benzenoid system $Z_{p}$, then

1. $\operatorname{Re} Z G_{1}\left(Z_{p}\right)=8 p+\frac{8}{3}$.

2. $\operatorname{Re} Z G_{2}\left(Z_{p}\right)=\frac{58}{5} p+\frac{2}{5}$.

3. $\operatorname{Re} Z G_{3}\left(Z_{p}\right)=368 p-98$. 
Proof. From Table 2.2, we have

$$
\begin{aligned}
\text { 1. } \operatorname{Re} Z G_{1}\left(Z_{p}\right) & =\sum_{u v \in E\left(T_{p}\right)} \frac{d_{u}+d_{v}}{d_{u} \cdot d_{v}} \\
& =\sum_{u v \in E_{\{2,2\}}\left(Z_{p}\right)} \frac{2+2}{2 \cdot 2}+\sum_{u v \in E_{\{2,3\}}\left(Z_{p}\right)} \frac{2+3}{2 \cdot 3}+\sum_{u v \in E_{\{3,3\}}\left(Z_{p}\right)} \frac{3+3}{3 \cdot 3} \\
& =\left|E_{\{2,2\}}\left(Z_{p}\right)\right| \frac{4}{4}+\left|E_{\{2,3\}}\left(Z_{p}\right)\right| \frac{5}{6}+\frac{6}{9}\left|E_{\{3,3\}}\left(Z_{p}\right)\right| \\
& =8 p+\frac{8}{3} . \\
\text { 2. } \operatorname{Re} Z G_{2}\left(Z_{p}\right) & =\sum_{u v \in E\left(Z_{p}\right)} \frac{d_{u} \cdot d_{v}}{d_{u}+d_{v}} \\
& =\sum_{u v \in E_{\{2,2\}}\left(Z_{p}\right)} \frac{2 \cdot 2}{2+2}+\sum_{u v \in E_{\{2,3\}}\left(Z_{p}\right)} \frac{2 \cdot 3}{2+3}+\sum_{u v \in E_{\{3,3\}}\left(Z_{p}\right)} \frac{3 \cdot 3}{3+3} \\
& =\left|E_{\{2,2\}}\left(Z_{p}\right)\right| \frac{4}{4}+\left|E_{\{2,3\}}\left(Z_{p}\right)\right| \frac{6}{5}+\frac{9}{6}\left|E_{\{3,3\}}\left(Z_{p}\right)\right| \\
& =\frac{58}{5} p+\frac{2}{5} \cdot \\
\text { 3. ReZG } G_{3}\left(Z_{p}\right) & =\sum_{u v \in E\left(Z_{p}\right)}\left(d_{u} \cdot d_{v}\right)\left(d_{u}+d_{v}\right) \\
& =\sum_{u v \in E_{\{2,2\}}\left(Z_{p}\right)}(2 \cdot 2)(2+2)+\sum_{u v \in E_{\{2,3\}}\left(Z_{p}\right)}(2 \cdot 3)(2+3) \\
& +\sum_{u v \in E_{\{3,3\}}\left(Z_{p}\right)}(3 \cdot 3)(3+3) \\
& =16\left|E_{\{2,2\}}\left(Z_{p}\right)\right|+30\left|E_{\{2,3\}}\left(Z_{p}\right)\right|+54\left|E_{\{3,3\}}\left(Z_{p}\right)\right| \\
& =368 p-98 .
\end{aligned}
$$

\subsection{Rhombic Benzenoid System}

Take another benzenoid system in which hexagons are arranged to form a rhombic shape $R_{n}$, in which there are $n$ rows of $n$ hexagons as given in Figure 2. Then it has $2 p(p+2)$ vertices and $3 p^{2}+4 p-1$ edges and the edge division is given in Table 2.3. 


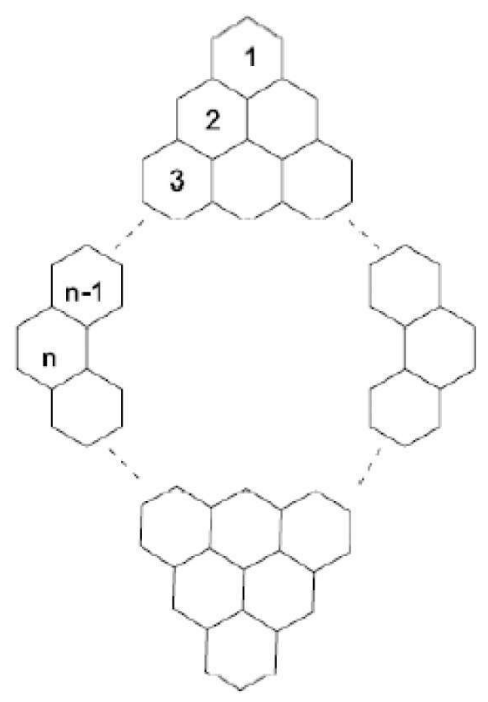

Figure 2.3: Graph of rhombic benzenoid system having $\mathrm{n}$ rows of $n$ hexagons [15]

Table 2.3: Edge Partition of rhombic benzenoid system

\begin{tabular}{|c|c|}
\hline$\left(d_{u}, d_{v}\right)$ & No of edges \\
\hline$(2,2)$ & 6 \\
\hline$(2,3)$ & $8(p-1)$ \\
\hline$(3,3)$ & $3 p^{2}-4 p+1$ \\
\hline
\end{tabular}

Theorem 2.3. Let $R_{p}$ be the Rhombic benzenoid system. Graph of $R_{p}$ has $p$ rows of $p$ hexagons and hexagons are arranged to form a rhombic shape.

1. $\operatorname{Re} Z G_{1}\left(R_{p}\right)=2 p^{2}+4 p$.

2. $R e Z G_{2}\left(R_{p}\right)=\frac{9}{2} p^{2}+\frac{18}{5} p-\frac{21}{10}$.

3. $\operatorname{Re} Z G_{3}\left(R_{p}\right)=162 p^{2}+24 p-90$. 
Redefined Zagreb Indices of Rhombic, triangular, Hourglass and... 859

Proof. $\quad$ Let $R_{p}$ be a Rhombic benzenoid. Then using Table 2.3

$$
\text { 1. } \begin{aligned}
\operatorname{Re} Z G_{1}\left(R_{p}\right) & =\sum_{u v \in E\left(R_{p}\right)} \frac{d_{u}+d_{v}}{d_{u} \cdot d_{v}} \\
& =\sum_{u v \in E_{\{2,2\}}\left(R_{p}\right)}^{\frac{2+2}{2 \cdot 2}}+\sum_{u v \in E_{\{2,3\}}\left(R_{p}\right)} \frac{2+3}{2 \cdot 3}+\sum_{u v \in E_{\{3,3\}}\left(R_{p}\right)} \frac{3+3}{3 \cdot 3} \\
& =\left|E_{\{2,2\}}\left(R_{p}\right)\right| \frac{4}{4}+\left|E_{\{2,3\}}\left(R_{p}\right)\right| \frac{5}{6}+\frac{6}{9}\left|E_{\{3,3\}}\left(R_{p}\right)\right| \\
& =2 p^{2}+4 p .
\end{aligned}
$$

2. $\operatorname{Re} Z G_{2}\left(R_{p}\right)=\sum_{u v \in E\left(R_{p}\right)} \frac{d_{u} \cdot d_{v}}{d_{u}+d_{v}}$

$$
\begin{aligned}
& =\sum_{u v \in E_{\{2,2\}}\left(R_{p}\right)}^{\frac{2 \cdot 2}{2+2}}+\sum_{u v \in E_{\{2,3\}}\left(R_{p}\right)} \frac{2 \cdot 3}{2+3}+\sum_{u v \in E_{\{3,3\}}\left(R_{p}\right)} \frac{3 \cdot 3}{3+3} \\
& =\left|E_{\{2,2\}}\left(R_{p}\right)\right| \frac{4}{4}+\left|E_{\{2,3\}}\left(R_{p}\right)\right| \frac{6}{5}+\frac{9}{6}\left|E_{\{3,3\}}\left(R_{p}\right)\right| \\
& =\frac{9}{2} p^{2}+\frac{18}{5} p-\frac{21}{10} .
\end{aligned}
$$

3. $R e Z G_{3}\left(R_{p}\right)=\sum_{u v \in E\left(R_{p}\right)}\left(d_{u} \cdot d_{v}\right)\left(d_{u}+d_{v}\right)$

$$
\begin{aligned}
& =\sum_{u v \in E_{\{2,2\}}\left(R_{p}\right)}(2 \cdot 2)(2+2)+\sum_{u v \in E_{\{2,3\}}\left(R_{p}\right)}(2 \cdot 3)(2+3) \\
& +\sum_{u v \in E_{\{3,3\}}\left(R_{p}\right)}(3 \cdot 3)(3+3) \\
& =16\left|E_{\{2,2\}}\left(R_{p}\right)\right|+30\left|E_{\{2,3\}}\left(R_{p}\right)\right|+54\left|E_{\{3,3\}}\left(R_{p}\right)\right| \\
& =162 p^{2}+24 p-90 .
\end{aligned}
$$




\subsection{Hourglass Benzenoid System}

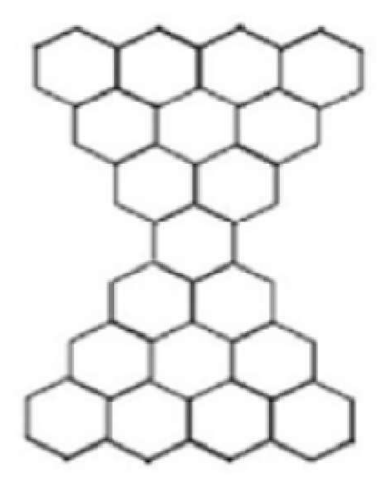

Figure 2.4: Benzenoid Hourglass system [15]

Let $X_{p}$ denotes the Benzenoid Hourglass (Figure 2.4) which is obtained from two copies of a triangular benzenoid $T_{p}$ by overlapping their external hexagons. Then we have,

$$
2\left(p^{2}+4 p-2\right) \text { edges and }\left|E\left(X_{p}\right)\right|=3 p^{2}+9 p-4 \text { vertices. }
$$

The edge partition of Hourglass benzenoid system is given in Table 2.4.

Theorem 2.4. Let $X_{p}$ denotes the Benzenoid Hourglass which is obtained from two copies of a triangular benzenoid $T_{p}$ by overlapping their external hexagons. Then

1. $\operatorname{Re} Z G_{1}\left(X_{p}\right)=2 p^{2}+8 p-\frac{8}{3}$. 
Table 2.4: Edge Partition of Hourglass benzenoid system

\begin{tabular}{|c|c|}
\hline$\left(d_{u}, d_{v}\right)$ & No of edges \\
\hline$(2,2)$ & 8 \\
\hline$(2,3)$ & $4(3 p-4)$ \\
\hline$(3,3)$ & $3 p^{2}-3 p+4$ \\
\hline
\end{tabular}

2. $\operatorname{Re} Z G_{2}\left(X_{p}\right)=\frac{9}{2} p^{2}+\frac{99}{10} p-\frac{26}{5}$.

3. $\operatorname{Re} Z G_{3}\left(X_{p}\right)=162 p^{2}+198 p-136$.

Proof. Now from Table 2.4, we have

1. $\operatorname{Re} Z G_{1}\left(X_{p}\right)=\sum_{u v \in E\left(X_{p}\right)} \frac{d_{u}+d_{v}}{d_{u} \cdot d_{v}}$

$$
\begin{aligned}
& =\sum_{u v \in E_{\{2,2\}}\left(X_{p}\right)}^{\frac{2+2}{2 \cdot 2}}+\sum_{u v \in E_{\{2,3\}}\left(X_{p}\right)} \frac{2+3}{2 \cdot 3}+\sum_{u v \in E_{\{3,3\}}\left(X_{p}\right)} \frac{3+3}{3 \cdot 3} \\
& =\left|E_{\{2,2\}}\left(X_{p}\right)\right| \frac{4}{4}+\left|E_{\{2,3\}}\left(X_{p}\right)\right| \frac{5}{6}+\frac{6}{9}\left|E_{\{3,3\}}\left(X_{p}\right)\right| \\
& =2 p^{2}+8 p-\frac{8}{3} .
\end{aligned}
$$

2. $\operatorname{Re} Z G_{2}\left(X_{p}\right)=\sum_{u v \in E\left(X_{p}\right)} \frac{d_{u} \cdot d_{v}}{d_{u}+d_{v}}$

$$
\begin{aligned}
& =\sum_{u v \in E_{\{2,2\}}\left(X_{p}\right)}^{\frac{2 \cdot 2}{2+2}}+\sum_{u v \in E_{\{2,3\}} v} \frac{2 \cdot 3}{2+3}+\sum_{u v \in E_{\{3,3\}}\left(X_{p}\right)} \frac{3 \cdot 3}{3+3} \\
& =\left|E_{\{2,2\}}\left(X_{p}\right)\right| \frac{4}{4}+\left|E_{\{2,3\}}\left(X_{p}\right)\right| \frac{6}{5}+\frac{9}{6}\left|E_{\{3,3\}}\left(X_{p}\right)\right| \\
& =\frac{9}{2} p^{2}+\frac{99}{10} p-\frac{26}{5} .
\end{aligned}
$$

3. $\operatorname{Re} Z G_{3}\left(X_{p}\right)=\sum_{u v \in E\left(X_{p}\right)}\left(d_{u} \cdot d_{v}\right)\left(d_{u}+d_{v}\right)$

$$
\begin{aligned}
& =\sum_{u v \in E_{\{2,2\}}\left(X_{p}\right)}(2 \cdot 2)(2+2)+\sum_{u v \in E_{\{2,3\}}\left(X_{p}\right)}(2 \cdot 3)(2+3) \\
& +\sum_{u v \in E_{\{3,3\}}\left(X_{p}\right)}(3 \cdot 3)(3+3) \\
& =16\left|E_{\{2,2\}}\left(X_{p}\right)\right|+30\left|E_{\{2,3\}}\left(X_{p}\right)\right|+54\left|E_{\{3,3\}}\left(X_{p}\right)\right| \\
& =162 p^{2}+198 p-136 .
\end{aligned}
$$

\subsection{Benzenoid Jagged-Rectangle}

Now we study Benzenoid jagged-rectangle shown in Figure 2.2. 
Table 2.5: Edge Partition of Jagged-rectangle benzenoid system

\begin{tabular}{|l|c|}
\hline$\left(d_{u}, d_{v}\right)$ & No of edges \\
\hline$(2,2)$ & $2 q+4$ \\
\hline$(2,3)$ & $4 p+4 q-4$ \\
\hline$(3,3)$ & $6 p q+p-5 q-4$ \\
\hline
\end{tabular}

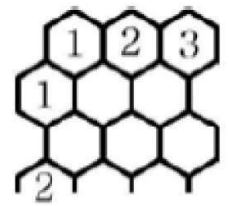

$\vdots$

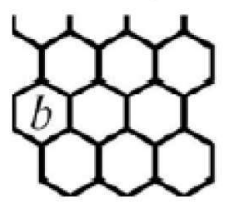

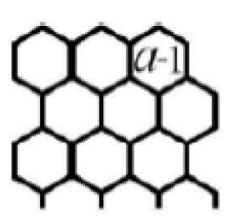

;

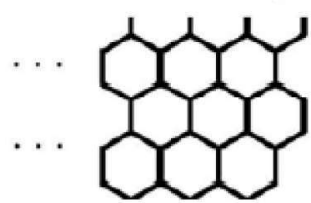

Figure 2.5: Benzenoid jagged-rectangle system [15]

Let $B_{p, q}$ denotes a Benzenoid system Jagged-rectangle for all $p, q \in N-$ 1. A Benzenoid Jagged-rectangle forms a rectangle and the number of benzenoids called in each chain alternate $\mathrm{p}$ and $\mathrm{p}-1$. The edge set of $B_{p, q}$ has three partitions given in Table 2.5.

Theorem 2.5. Let $B_{p, q}$ denotes a Benzenoid system Jagged-rectangle for all $p, q \in N-1$. Then

1. $\operatorname{Re} Z G_{1}\left(B_{p, q}\right)=6 p q+4 p+2 q-2$.

2. $\operatorname{Re} Z G_{2}\left(B_{p, q}\right)=6 p q+\frac{63}{10} p-\frac{7}{10} q-\frac{34}{5}$.

3. $\operatorname{Re} Z G_{3}\left(B_{p, q}\right)=6 p q+174 p-118 q-272$. 
Proof. Let $B_{p, q}$ denotes a Benzenoid system Jagged-rectangle for all $p, q \in N-1$. Then from Table 2.5, we have

$$
\text { 1. } \begin{aligned}
\operatorname{Re} Z G_{1}\left(B_{p, q}\right) & =\sum_{u v \in E\left(B_{p, q}\right)} \frac{d_{u}+d_{v}}{d_{u} \cdot d_{v}} \\
& =\sum_{u v \in E_{\{2,2\}}\left(B_{p, q}\right)} \frac{2+2}{2 \cdot 2}+\sum_{u v \in E_{\{2,3\}}\left(B_{p, q}\right)} \frac{2+3}{2 \cdot 3}+\sum_{u v \in E_{\{3,3\}}\left(B_{p, q}\right)} \frac{3+3}{3 \cdot 3} \\
& =\left|E_{\{2,2\}}\left(B_{p, q}\right)\right| \frac{4}{4}+\left|E_{\{2,3\}}\left(B_{p, q}\right)\right| \frac{5}{6}+\frac{6}{9}\left|E_{\{3,3\}}\left(B_{p, q}\right)\right| \\
& =6 p q+4 p+2 q-2 .
\end{aligned}
$$

2. $\operatorname{Re} Z G_{2}\left(B_{p, q}\right)=\sum_{u v \in E\left(B_{p, q}\right)} \frac{d_{u} \cdot d_{v}}{d_{u}+d_{v}}$

$$
\begin{aligned}
& =\sum_{u v \in E_{\{2,2\}}\left(B_{p, q}\right)} \frac{2 \cdot 2}{2+2}+\sum_{u v \in E_{\{2,3\}}\left(B_{p, q}\right)} \frac{2 \cdot 3}{2+3}+\sum_{u v \in E_{\{3,3\}}\left(B_{p, q}\right)} \frac{3 \cdot 3}{3+3} \\
& =\left|E_{\{2,2\}}\left(B_{p, q}\right)\right| \frac{4}{4}+\left|E_{\{2,3\}}\left(B_{p, q}\right)\right| \frac{6}{5}+\frac{9}{6}\left|E_{\{3,3\}}\left(B_{p, q}\right)\right| \\
& =6 p q+\frac{63}{10} p-\frac{7}{10} q-\frac{34}{5} .
\end{aligned}
$$

3. $\operatorname{Re} Z G_{3}\left(B_{p, q}\right)=\sum_{u v \in E\left(B_{p, q}\right)}\left(d_{u} \cdot d_{v}\right)\left(d_{u}+d_{v}\right)$

$$
\begin{aligned}
& =\sum_{u v \in E_{\{2,2\}}\left(B_{p, q}\right)}(2 \cdot 2)(2+2)+\sum_{u v \in E_{\{2,3\}}\left(B_{p, q}\right)}(2 \cdot 3)(2+3) \\
& +\sum_{u v \in E_{\{3,3\}}\left(B_{p, q}\right)}(3 \cdot 3)(3+3) \\
& =16\left|E_{\{2,2\}}\left(B_{p, q}\right)\right|+30\left|E_{\{2,3\}}\left(B_{p, q}\right)\right|+54\left|E_{\{3,3\}}\left(B_{p, q}\right)\right| \\
& =6 p q+174 p-118 q-272 .
\end{aligned}
$$

\section{Concluding remarks and Geometric Comparison}

In this paper we computed redefined first, second and third Zagreb indices of Rhombic, triangular, Hourglass and Jagged-rectangle benzenoid systems. We computed some special values of these redefined Zagreb indices for special values of involved parameters. Following Figures 3.1, 3.2 and 3.3 show the dependence of our results on the involved parameters. With the help of these graphs we can chose that which benzenoid system has maximum or minimum value of a particular topological index $[1,6,8,9,10]$. 


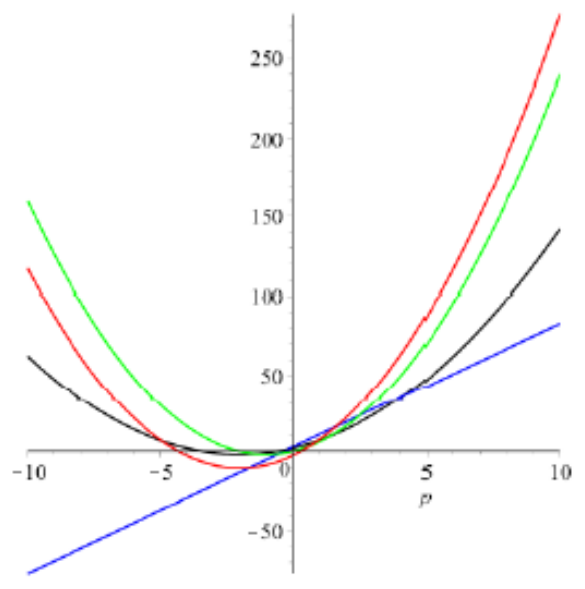

Figure 3.1: Plots of first redefined Zagreb index

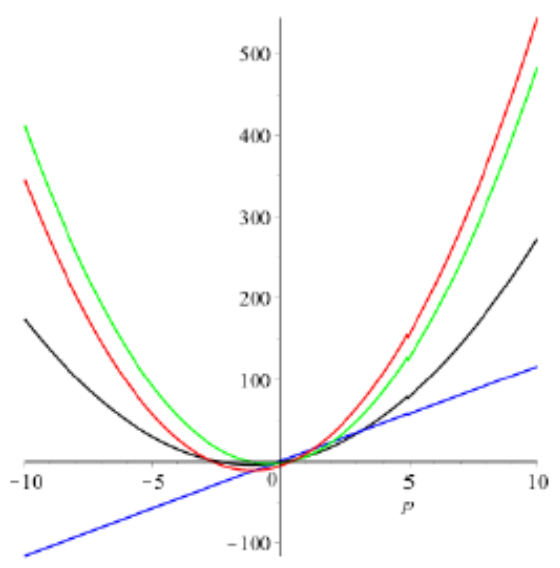

Figure 3.2: Plots of second redefined Zagreb index 


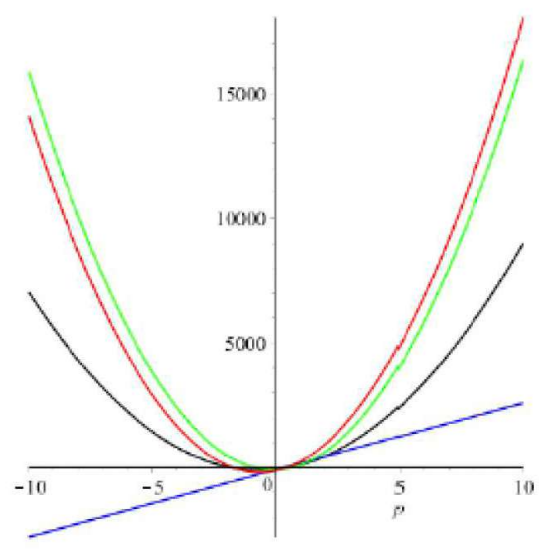

Figure 3.3: Plots of third redefined Zagreb index

\section{References}

[1] S. Ahmad, H. M. A. Siddiqui, A. Ali, M. R. Farahani, M. Imran, and I. N. Cangul, "On Wiener index and Wiener polarity index of some polyomino chains", Journal of discrete mathematical sciences and cryptography, vol. 22, no. 7, pp. 1151-1164, 2019, doi: 10.1080/09720529.2019.1688965

[2] A. Ali, W. Nazeer, M. Munir, and S. M. Kang, "M-polynomials and topological indices of zigzag and rhombic Benzenoid systems", Open chemistry, vol. 16, no. 1, pp. 73-78, Jan. 2018, doi: 10.1515/chem-2018-0010

[3] U. Ali, Y. Ahmad, and M. S. Sardar, "On 3-total edge product cordial labeling of tadpole, book and flower graphs", Open journal of mathematical sciences, vol. 4, no. 1, pp. 48-55, 2020, doi: 10.30538/oms2020.0093

[4] F. Asif, Z. Zahid, and S. Zafar, "Leap Zagreb and leap hyper-Zagreb indices of Jahangir and Jahangir derived graphs", Engineering and applied science letter, vol. 3, no. 2, pp. 1-8, 2020. [On line]. Available: https://bit.ly/3dm05rH 
[5] A. T. Balaban, I. Motoc, D. Bonchev, and O. Mekenyan, "Topological indices for structure-activity correlations", in Steric effects in drug design, vol. 114, Berlin: Springer, 1983, pp. 21-55, doi: 10.1007/BFb0111212

[6] M. Cancan, S. Ediz, and M. R. Farahani, "On ve-degree atom-bond connectivity, sum-connectivity, geometric-arithmetic and harmonic indices of copper oxide", Eurasian chemical communications, vol. 2, no. 5, pp. 641-645, 2020, doi: 10.33945/SAMI/ECC.2020.5.11

[7] B. Furtula, A. Graovac, and D. Vukičević, "Augmented zagreb index", Journal of mathematical chemistry, vol. 48, no. 2, pp. 370-380, Aug. 2010, doi: 10.1007/s10910-010-9677-3

[8] W. Gao and M. R. Farahani, "The hyper-zagreb index for an infinite family of nanostar dendrimer", Journal of discrete mathematical sciences and cryptography, vol. 20, no. 2, pp. 515-523, 2017, doi: 10.1080/09720529.2016.1220088

[9] W. Gao and M. R. Farahani, "The zagreb topological indices for a type of benzenoid systems jagged-rectangle", Journal of interdisciplinary mathematics, vol. 20, no. 5, pp. 1341-1348, 2017, doi: 10.1080/09720502.2016.1232037

[10] W. Gao, L. Shi, and M. R. Farahani, "Szeged Related Indices of $\mathrm{TUAC}_{6}[\mathrm{p}, \mathrm{q}]$ ", Journal of discrete mathematical sciences and cryptography, vol. 20, no. 2, pp. 553-563, 2017, doi: $10.1080 / 09720529.2016 .1228312$

[11] W. Gao, M. Younas, A. Farooq, A. Virk, and W. Nazeer, "Some reverse degree-based topological indices and polynomials of dendrimers", Mathematics, vol. 6, no. 10, Art ID. 214, Oct. 2018, doi: 10.3390/math6100214

[12] I. Gutman, B. Rucić, N. Trinajstić, and C. F. Wilcox Jr. "Graph theory and molecular orbitals. XII. Acyclic polyenes", The journal of chemical physics, vol. 62, no. 9, Art ID. 3399, May 1975, doi: 10.1063/1.430994

[13] I. Gutman and N. Trinajstić, "Graph theory and molecular orbitals. Total $\varphi$-electron energy of alternant hydrocarbons", Chemical physics letters, vol. 17, no. 4, pp. 535-538, Dec. 1972, doi: 10.1016/00092614(72)85099-1 
[14] Y. Huang, B. Liu and L. Gan, "Augmented zagreb index of connected graphs", MATCH communication in mathematical and in computer chemistry, vol. 67, no. 2, pp. 483-494, 2012. [On line]. Available: https://bit.ly/2NdkHYe

[15] Y. C. Kwun, A. Ali, W. Nazeer, M. A. Chaudhary, and S. M. Kang, "M-polynomials and degree-based topological indices of triangular, Hourglass, and Jagged-Rectangle Benzenoid systems", Journal of chemistry, vol. 2018, Art ID. 8213950, Dec. 2018, doi: 10.1155/2018/8213950

[16] J.-B. Liu, M. Younas, M. Habib, M. Yousaf, and W. Nazeer, "M-polynomials and degree-based topological indices of $\mathrm{VC}_{5} \mathrm{C}_{7}[\mathrm{p}, \mathrm{q}]$ and $\mathrm{HC}_{5} \mathrm{C}_{7}[\mathrm{p}, \mathrm{q}]$ Nanotubes", IEEE access, vol. 7, pp. 41125-41132, Mar. 2019, doi: 10.1109/ACCESS.2019.2907667

[17] M. Munir, W. Nazeer, S. Rafique, and S. Kang, "M-polynomial and degree-based topological Indices of polyhex nanotubes", Symmetry, vol. 8, no. 12, Art ID. 149, 2016, doi: 10.3390/sym8120149

[18] P. S. Ranjini, V. Lokesha, and A. Usha, "Relation between phenylene and hexagonal squeeze using harmonic index", International journal of graph theory; vol. 1, pp-116-121, 2013

[19] A. Shah and S. A. U. H. Bokhary, "On chromatic polynomial of certain families of dendrimer graphs", Open journal of mathematical sciences, vol. 3, no. 1, pp. 404-416, 2019, doi: 10.30538/oms2019.0083

[20] A. Tabassum, M. A. Umar, M. Perveen, and A. Raheem, "Antimagicness of subdivided fans", Open journal of mathematical sciences, vol. 4, no. 1, pp. 18-22, 2020, doi: 10.30538/oms2020.0089

[21] M. A. Umar, N. Ali, A. Tabassum, and B. R. Ali, "Book graphs are cycle antimagic", Open journal of mathematical sciences, vol. 3, no. 1, pp. 184190, 2019, doi: 10.30538/oms2019.0061 